\title{
Perception of Recurrent Stroke Risk among Black, White and Hispanic Ischemic Stroke and Transient Ischemic Attack Survivors: The SWIFT Study
}

\author{
Bernadette Boden-Albala ${ }^{a} b$ Heather Carman ${ }^{a}$ Megan Moran ${ }^{a}$ \\ Margaret Doyle ${ }^{a}$ Myunghee C. Paik ${ }^{c}$

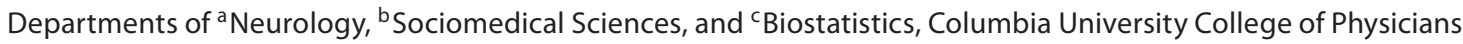 \\ and Surgeons and Mailman School of Public Health, New York, N.Y., USA
}

\section{Key Words}

Risk perception $\cdot$ Stroke knowledge $\cdot$ Health beliefs

\begin{abstract}
Objectives: Risk modification through behavior change is critical for primary and secondary stroke prevention. Theories of health behavior identify perceived risk as an important component to facilitate behavior change; however, little is known about perceived risk of vascular events among stroke survivors. Methods: The SWIFT (Stroke Warning Information and Faster Treatment) study includes a prospective population-based ethnically diverse cohort of ischemic stroke and transient ischemic attack survivors. We investigate the baseline relationship between demographics, health beliefs, and knowledge on risk perception. Regression models examined predictors of inaccurate perception. Results: Only $20 \%$ accurately estimated risk, $10 \%$ of the participants underestimated risk, and $70 \%$ of the 817 study participants significantly overestimated their risk for a recurrent stroke. The mean perceived likelihood of recurrent ischemic stroke in the next 10 years was $51 \pm 7 \%$. We found no significant differences by race-ethnicity with regard to accurate estimation of risk. Inaccurate estimation of risk was associated with attitudes and beliefs [worry $(p<0.04)$, fatalism $(p<0.07)]$ and memory problems $(p<0.01)$, but not history or knowledge of vascular risk factors. Conclusion: This paper
\end{abstract}

provides a unique perspective on how factors such as belief systems influence risk perception in a diverse population at high stroke risk. There is a need for future research on how risk perception can inform primary and secondary stroke prevention.

Copyright $\odot 2011$ S. Karger AG, Basel

\section{Introduction}

Risk factor modification through lifestyle behavior change is important for stroke prevention. Theories of health behavior identify perceived risk as a key component in facilitating behavior change [1,2]. Research on behavior change suggests that patients with accurate perceptions of risk are more likely to comply with prevention practices compared to those with inaccurate perceptions [2]. Underestimation of risk or 'optimistic bias' may undermine prevention strategies. Perceived risk may also be overestimated leading to difficulty in communication, excess patient anxiety and fear [3-7]. Accurate perception of risk provides a valuable foundation to begin behavior modification strategies to reduce risk [2-7]. There is no standardized health literacy measure to determine perception of risk and varying strategies have been employed to capture patient risk perception. Risk perception is captured as 'low, medium, high'; or as a comparison to aver-

\section{KARGER}

(C) 2011 S. Karger AG, Basel

Fax +41613061234 E-Mail karger@karger.ch www.karger.com
Accessible online at: www.karger.com/ned
Dr. B. Boden-Albala Neurological Institute 710 West 168 Street

New York, NY 10032 (USA)

Tel. +1 212305 0501, E-Mail bb87@columbia.edu 
age [6-12]. Few studies ask patients to quantify risk or have examined the relationship between risk perception and factors such as health beliefs [5-10]. This study seeks to explore stroke risk perception in an ethnically diverse population of individuals with recent ischemic stroke or transient ischemic attack (TIA) and to examine the relationship between stroke risk perception and demographics, health beliefs, stroke knowledge and risk factors.

\section{Materials and Methods}

The overall objective of the SWIFT (Stroke Warning Information and Faster Treatment) study was to evaluate the efficacy of an interactive stroke preparedness educational program on improved times to the emergency department using a randomized controlled trial design described elsewhere [13]. Participants were enrolled in the prospective SWIFT study at Columbia University Medical Center. Eligibility for the SWIFT study included a diagnosis of ischemic stroke or TIA, over 18 years of age, ability to consent, and residing in Northern Manhattan. $\mathrm{Pa}$ tients were excluded if they were unable to give informed consent, discharged to a nursing home or requiring 24-hour care, if they had a modified Rankin scale score $>4$ at baseline, severe aphasia limiting comprehension, prestroke dementia history, or end-stage disease resulting in probable mortality $\leq 1$ year. Subjects had to be able to participate in an intervention session given in either English or Spanish. The NIHSS score ranged from 0 to 17 with a mean close to 1 . Less than $10 \%$ of the eligible patients refused participation [13]. All data in this article represent information from the baseline preintervention interview. After informed consent, a structured in-person interview, including demographic information and validated surveys, was performed in English or Spanish. Standardized questions were adapted from the Behavioral Risk Factor Surveillance System [14]. Measurements of blood pressure, height, weight, hip and waist were recorded. The health belief questions asked the participants to agree or disagree to the following statements: 'Some people are more likely to have a stroke than others'; 'I can protect myself from having a stroke'; 'If I follow my doctor's advice I will be less likely to have a stroke'; 'I worry about having a stroke', and 'Some people are fated to suffer a stroke and there is nothing that can be done to prevent this' [13].

\section{Measurement of Risk Perception}

Patients were asked to quantify their 10 -year stroke risk using a verbally administered scale of $0-10$ (with 0 being extremely unlikely and 10 being extremely likely). We defined accurate estimation of recurrent events to be $20-40 \%$, which was selected after a literature review and our experience in recurrent events in the community [15-19]. Underestimation was defined as risk perception of $<2$, and overestimation was defined as risk perception of $>4$.

\section{Statistics}

We evaluated the relationship between perceived stroke risk and factors including health beliefs, knowledge, and risk factors by testing bivariate associations between variables and perceived stroke risk. We performed a multivariate logistic regression analysis to examine factors associated with inaccurate risk perception adjusting for age, gender, race-ethnicity and significant factors $(\mathrm{p}<0.1)$ from univariate analysis. The perceived risks categorized into underestimated (0-1), accurate (2-4) and overestimated (510) were dichotomized into accurate versus inaccurate for the multivariate model.

\section{Results}

The first 817 SWIFT study participants were used for this analysis. All data in this article represent information from the baseline prerandomization interview. Mean age was $63 \pm 12$ years; $50 \%$ were female; $46 \%$ Hispanic; $27 \%$ white; $23 \%$ black; $4 \%$ other. Three quarters of participants were diagnosed with ischemic stroke and $25 \%$ were diagnosed with TIA. Only $44 \%$ of the participants completed high school.

The mean perceived likelihood of having a stroke in 10 years was $51 \%$, (median, $50 \%$ ), or $5 \%$ per year. Only $20 \%$ of participants accurately estimated risk of recurrent events. The majority of participants (70\%) overestimated their recurrent stroke risk but $10 \%$ reported no perceived risk. We found no significant differences by race-ethnicity with regard to accurate estimation of risk. In univariate analysis (table 1), we report that greater perception of stroke risk was associated with individuals who agreed with the statements, 'Some people are fated to suffer strokes and there is nothing that can be done to prevent them', or 'I worry about having a stroke'. Poorer educational experience was also associated with risk overestimation. Vascular risk factors associated with greater perception included diabetes, previous ischemic stroke, presence of two or more risk factors, and memory problems. Stroke and risk factor knowledge of individual risk were not associated with higher risk perception.

The multivariate model demonstrated that inaccurate estimation of risk ( $<20$ or $>40 \%)$ was significantly associated with health beliefs such as worry as well as a statistical trend for fatalistic beliefs. Participants reporting they could 'protect themselves from a stroke' were significantly more likely to accurately estimate recurrent risk events. Self-reported memory problems were significantly associated with inaccurate risk perception. Vascular risk knowledge or information was not associated with risk perception but a trend for inaccurate estimation was seen among those with prior stroke or TIA (table 2). Educational level and race-ethnic differences were attenuated in the multivariate model. 
Table 1. Bivariate analysis examining associations between risk perception and health beliefs, risk factors and demographics: the SWIFT study

\begin{tabular}{|c|c|c|c|c|c|}
\hline & \multicolumn{2}{|c|}{ Positive response } & \multicolumn{2}{|c|}{ Negative response } & \multirow[t]{2}{*}{$\mathrm{p}$ value } \\
\hline & number & $\begin{array}{l}\text { mean } 10 \text {-year } \\
\text { risk estimate, } \%\end{array}$ & number & $\begin{array}{l}\text { mean } 10 \text {-year } \\
\text { risk estimate, \% }\end{array}$ & \\
\hline \multicolumn{6}{|l|}{ Health beliefs } \\
\hline Fated to have a stroke & 274 & 54 & 445 & 49 & $0.04^{\mathrm{a}}$ \\
\hline Protect from stroke & 542 & 49 & 178 & 54 & 0.15 \\
\hline Worry about stroke & 485 & 54 & 235 & 45 & $0.00^{\mathrm{a}}$ \\
\hline Some are more likely to have a stroke & 603 & 51 & 115 & 49 & 0.25 \\
\hline Follow doctor's advice about stroke & 677 & 49 & 41 & 53 & 0.79 \\
\hline \multicolumn{6}{|l|}{ Knowledge of risk factors } \\
\hline Knowledge of hypertension as a risk factor & 684 & 50 & 36 & 48 & 0.87 \\
\hline Knowledge of diabetes as a risk factor & 568 & 51 & 152 & 47 & 0.13 \\
\hline Knowledge of obesity as a risk factor & 619 & 51 & 101 & 48 & 0.20 \\
\hline Knowledge of family history as a risk factor & 634 & 51 & 86 & 47 & 0.55 \\
\hline Knowledge of smoking as a risk factor & 621 & 51 & 99 & 48 & 0.47 \\
\hline Trouble with memory & 300 & 50 & 427 & 47 & $0.00^{\mathrm{a}}$ \\
\hline \multicolumn{6}{|l|}{ Demographics } \\
\hline Greater than high school education & 391 & 48 & 293 & 53 & $0.02^{\mathrm{a}}$ \\
\hline Black versus white & 164 & 51 & 191 & 50 & 0.89 \\
\hline Hispanic versus white & 339 & 51 & 191 & 50 & 0.99 \\
\hline Medicaid versus private/other & 265 & 49 & 448 & 52 & 0.40 \\
\hline \multicolumn{6}{|l|}{ Risk factors } \\
\hline Age $>65$ years & 322 & 50 & 393 & 50 & 0.79 \\
\hline Physical activity & 362 & 51 & 358 & 50 & 0.50 \\
\hline Hypertension & 524 & 51 & 196 & 48 & 0.17 \\
\hline Diabetes & 258 & 53 & 459 & 49 & 0.09 \\
\hline Family history of stroke & 131 & 54 & 582 & 50 & 0.15 \\
\hline Family history of heart attack & 111 & 55 & 603 & 50 & 0.13 \\
\hline Smoker & 434 & 52 & 287 & 49 & 0.18 \\
\hline Two or more risk factors for stroke & 396 & 52 & 323 & 48 & $0.08^{\mathrm{b}}$ \\
\hline Previous stroke & 118 & 58 & 592 & 49 & 0.10 \\
\hline
\end{tabular}

${ }^{a}$ Significant at the $\mathrm{p}<0.05$ level. ${ }^{\mathrm{b}}$ Trend at the $\mathrm{p}<0.08$ level.

\section{Discussion}

Our results (the mean perceived likelihood of having a stroke in 10 years being 50\%) suggest that patients in our ischemic stroke cohort perceive themselves to be at high risk of recurrent stroke over the next decades. This finding is contradictory to previous research which report that individuals at high risk underestimate stroke risk [6-9]. In a family practice cohort, $11 \%$ of patients at significant stroke risk recognized their increased risk; $48 \%$ reported average risk, and $41 \%$ below average risk [7]. Another study reported that less than half of individuals with a minor stroke/TIA considered themselves to be at increased vascular risk [12]. Among the studies reporting underestimation, risk was most often assessed in a qualitative manner. These studies asked patients to rate risk perception as lower than average/average/or higher than average or they were simply asked: 'Do you believe that you are at risk of stroke?' [2-12]. Indeed, the manner in which the question of risk perception is presented may alter the risk estimate. In another study of 1,557 individuals at high vascular risk but with no diagnosed atherosclerotic disease, participants significantly overestimated their 10-year risk of stroke. Ten-year risk was assessed using a visual analogue scale between 0 and $100 \%$. The mean perceived 10 -year risk was $31 \%$ for myocardial infarction and $30 \%$ for stroke [5]. One quarter of participants did not provide risk estimates [5]. Pre- 
Table 2. Multivariate model of perceived 10-year ischemic stroke risk

\begin{tabular}{lcl}
\hline Variable & Estimate & $\mathrm{p}$ value \\
\hline Fated to suffer a stroke & 0.434 & $0.07^{\mathrm{b}}$ \\
Protect from a stroke & -0.584 & $0.04^{\mathrm{a}}$ \\
Worry about stroke & 10.3 & $0.006^{\mathrm{a}}$ \\
Hispanic versus white & -0.419 & 0.2 \\
Black versus white & -0.153 & 0.5 \\
Memory problems & 0.618 & $0.01^{\mathrm{a}}$ \\
Education > high school & -0.402 & 0.1 \\
Identifies obesity risk factor for stroke & 0.509 & 0.1 \\
Has >2 risk factors for stroke & 0.358 & 0.1 \\
Previous ischemic stroke or TIA & 0.565 & $0.07^{\mathrm{b}}$ \\
\hline
\end{tabular}

${ }^{\text {a }}$ Significant at the $\mathrm{p}<0.05$ level. ${ }^{\mathrm{b}}$ Trend at $\mathrm{p}<0.08$ level.

dictors of risk overestimation included older age, smoking, family history of vascular disease and self-rated fair/poor health [5]. The participants in our SWIFT study were asked about risk perception using a similar methodology and likewise were likely to overestimate recurrent stroke risk.

People react to risk at two levels; they evaluate risk cognitively and they react to it emotionally [20]. Poststroke cognitive decline may alter risk perception [20]. Indeed, we report that prestroke memory problems were significantly associated with increased risk perception. Emotional processes and affective factors such as worry and how people feel about risk influence risk perception [20-22]. In our study, those who worry about stroke or feel they are fated to have a stroke were more likely to overestimate risk. Beliefs of 'fatalism' have been associated with Hispanic culture and may be important in influencing risk perception in our largely Hispanic cohort $[23,24]$. Individuals may overestimate risk when they feel they have little to no control over the risk [2]. Lay populations may view information about the 'brain' as extremely complex and overlaid with cultural nuances resulting in feelings of intimidation and loss of control.

Theories of health behavior identify perceived risk as an important component to facilitate behavior change. Several intervention studies report that risk perception change is associated with improvement of health behaviors $[2,25]$. Adequate estimates of risk provide the individual with a sense of control while both underestimation and overestimation of risk may lead to behaviors counter to health and wellness. For stroke prevention, the focus has been on increasing knowledge and eliminating underestimation of risk, but risk theory suggests that overestimation is also problematic. Specifically, overestimation of stroke risk may leave individuals feeling overwhelmed and unable to modify vascular risk factors. Indeed, feeling out of control can also actually promote continuation of bad health behaviors such as sedentary life choices, poor adherence and unhealthy eating.

Limitations of the study include selection bias because of the exclusion criteria of the randomized controlled trial design, potential overestimation bias due to surveying hospitalized participants as the acute setting may heighten awareness or fear of a future stroke and estimate of recurrent stroke risk in the $20-40 \%$ range based on literature and experience [15-19]. This study highlights the importance of health beliefs and attitudes on risk perception.

\section{Acknowledgements}

The authors would like to thank the NINDS for funding of this work through the SPOTRIAS funding mechanism NIH NINDS P50 NS049060 P 3.

\section{References}

1 Weinstein N: Testing four competing theories of health-protective behavior. Health Psychol 1993;12:324-333.

-2 Kreuter M, Strecher V: Changing inaccurate perceptions of health risk: results from a randomized trial. Health Psychol 1995;14:56-63.

$\checkmark 3$ Weinstein ND: Unrealistic optimism about illness susceptibility: conclusions from a community wide sample. J Behav Med 1989; 10:481-500.
4 Weijden TV, Steenkiste BV, Stoffers HEJH, Timmermans DRM, Grol R: Primary prevention of cardiovascular diseases in general practice: mismatch between cardiovascular risk and patients' risk perceptions. Med Decis Making 2007;27:754-761.

5 Frijling BD, Lobl CM, Keus IM, Jenks KM, Akkermans RP, Hulscher ME, Prins JL, van der Wouden JC, Grol R: Perceptions of cardiovascular risk among patients with hypertension or diabetes. Patient Educ Couns 2004;52:47-53.
6 Kraywinkel K, Heidrich J, Heuschmann PU, Wagner M, Berger K: Stroke risk awareness among participants of a stroke awareness campaign. BMC Public Health 2007;7:39.

-7 Samsa GP, Cohen SJ, Goldstein LB, Bonito AJ, Duncan PW, Enarson C, DeFriese GH, Horner RD, Matchar DB: Knowledge of risk among patients at increased risk for stroke. Stroke 1997;28:916-921. 
8 Powers B, Oddone E, Grubber J, Olsen M, Bosworth $\mathrm{H}$ : Perceived and actual stroke risk among men with hypertension. J Clin Hypertens 2008;10:287-294.

-9 Uruzar GG, Sears SF: Psychosocial and cultural influences on cardiovascular health and quality of life among Hispanic cardiac patients in South Florida. J Behav Med 2006; 29:255-268.

-10 Perez-Stable EJ, Napoles-Springer A, Miramontes JM: The effects of ethnicity and language on medical outcomes of patients with hypertension or diabetes. Med Care 1997;35: 1212-1219.

-11 Yoon SS, Heller RF, Levi C, Wiggers J: Knowledge and perception about stroke among an Australian urban population. BMC Public Health 2001;1:14.

$\checkmark 12$ Kothari R, Sauerbeck L, Jauch E, Broderick J, Brott T, Khoury J, Liu T: Patients' awareness of stroke signs, symptoms and risk factors. Stroke 1997;28:1871-1875.

13 Boden-Albala B, Stillman J, Perez T, Evensen L, Moats H, Wright C, Moon-Howard J, Doyle M, Paik MC: Stroke preparedness RCT in a multi-ethnic cohort: design and methods. Contemp Clin Trials 2010;31:235241.
14 Gentry E, Kalsbeek W, Hooelin G, Jones J: The Behavioral Risk Factor Surveys. 2. Design, methods, and estimates form a combined data set. Am J Prev Med 1985;1:9-14.

15 Burn J, Dennis M, Bamford J, Sandercock P, Wade D, Warlow C: Long-term risk of recurrent stroke after a first-ever stroke. The Oxfordshire Community Stroke Project. Stroke 1995;25:333-337.

16 Hankey G, Jamrozik K, Broadhurst R, Forbes S, Burvill P, Anderson C, Stewart-Wynne E: Long-term risk of first recurrent stroke in the Perth community. Stroke 1998;29:24912500.

17 Petty G, Brown R, Whisnunt J, Sicks J, O'Fallon N, Wibers D: Survival and recurrence after first cerebral infarction: a population-based study in Rochester, Minnesota, 1975 through 1989. Neurology 1998;50:208216.

$>18$ Hardie K, Hankey G, Jamrozik K, Broadhurst R, Anderson C: Ten-year risk of first recurrent stroke and disability after first-ever stroke in the Perth Community Stroke Study. Stroke 2004;35:731-735.

19 Dhamoon MS, Sciacca RR, Rundek T, Sacco RL, Elkind MS: Recurrent stroke and cardiac risks after first ischemic stroke: the Northern Manhattan Study. Neurology 2006;66: 641-646.
20 Loewenstein G, Weber E, Hsee C, Welch N: Risk as feelings. Psychol Bull 2001;127:267286.

21 Klein W, Cerully J: Health-related risk perception and decision-making: lessons from the study of motives in social psychology. Soc Personal Psychol Compass 2007;1:334-358.

22 Slovic P, Finulane M, Peters E, MacGregor D: Risk as analysis and risk as feelings: some thoughts about affect, reason, risk and rationality. Risk Anal 2004;24:311-322.

23 Neff JA, Hoppe SK: Race/ethnicity, acculturation, and psychological distress: fatalism and religiosity as cultural resources. J Community Psychol 1993;21:3-20.

24 Cueller I, Arnold B, Maldonado R: Acculturation rating scale for Mexican Americans. 2. A revision of the original ARSMA scale. Hisp J Behav Sci 1995;17:275-304.

25 Tate RB, Fernandez N, Yassi Y, Canizares Y, Spiegel J, Bonet M: Change in health risk perception following community intervention in Central Havana, Cuba. Health Promot Int 2003;18:279-286 